\title{
Factors influencing mortality from infective endocarditis in two district general hospitals
}

\author{
D. McGivern, P. Ispahani ${ }^{1}$ and D. Banks \\ City Hospital and 'Department of Microbiology and Public Health Laboratory, Nottingham, UK.
}

\begin{abstract}
Summary: Factors influencing mortality were studied in 92 consecutive cases of infective endocarditis admitted to two district general hospitals between January 1975 and April 1982. Thirty two patients died, an overall mortality of $35 \%, 13$ patients died before diagnosis and 19 despite aggressive antimicrobial therapy. Bactericidal antibiotic levels were monitored in 39 cases but these did not appear to influence outcome.

Mortality was lowest for Streptococcus viridans infection (15\%) but rose to $50 \%$ for infections with $S$. faecalis and other less common organisms. Most deaths were in patients over 50 . Cardiac failure on admission was a poor predictor of mortality, although this was the principal cause of death during treatment (14 cases) . Eight patients had emergency valve replacement and 3 died post-operatively.

When the diagnosis was missed during life (13 cases) arterial embolus was a common presenting feature (46\%). Classical signs of endocarditis, other than pyrexia, were absent. A cardiac murmur (always mitral incompetence) was noted in only 6 cases and considered to be insignificant.
\end{abstract}

\section{Introduction}

Following the introduction of antibiotics, mortality from infective endocarditis fell, but remains at $14-$ $46 \%$ in Great Britain. ${ }^{1-3}$ Possible causes of variation in reported mortality include differences in the types of hospital from which the patients were recruited (e.g. regional cardiological centre or district general hospital), and in the age distribution of cases in the reported series. We report the general clinical findings and discuss the factors influencing outcome in an unselected group of patients presenting at two district general hospitals in the Midlands.

\section{Methods}

Cases of infective endocarditis admitted to two Nottingham hospitals between January 1975 and April 1982 were identified by examining medical, microbiological and post-mortem records.

Cases were included if positive blood cultures or serology were obtained with clinical evidence of endocarditis; if, despite negative blood cultures, there was strong clinical evidence of endocarditis (fever, changing heart murmur and splinter haemorrhages); or if typical endocarditic lesions were detected at

Correspondence: D. McGivern, B.M., M.R.C.P., Bristol Royal Infirmary, Bristol BS2 8HW, UK.

Accepted: 22 October 1986 autopsy and histological or bacteriological examination of the lesions confirmed the presence of infection.

Minimum inhibitory and minimum bactericidal concentrations of antibiotics were determined by the tube dilution method for most bacterial isolates. The bactericidal activity of the patient's serum against the organism isolated was determined during treatment, before (trough level) and 1 hour after (peak level) an antibiotic dose.

\section{Results}

There were 92 cases of infective endocarditis during the study period. Thirty two patients died $(35 \%)$ including 13 patients in whom the diagnosis was missed during life.

Of the 79 patients in whom the diagnosis of endocarditis was established in life, 44 were men and 35 were women. There was a peak incidence in patients aged 61-70 (Figure 1). Only 3 of the 28 patients aged 50 or less died, whereas 16 of 51 patients over the age of 50 died. Mortality in men ( 15 deaths) exceeded that in women (4 deaths).

\section{Predisposing causes}

Twenty-three of the total 92 patients were known to have had rheumatic heart disease and a further 22 
patients had a known heart murmur, usually mitral incompetence. Seven patients had congenital heart lesions and 8 had prosthetic heart valves. The remaining 32 patients $(35 \%)$ were not known to have had valvular heart disease.

Only 4 patients presented following dental manipulation, 3 of whom had infection with viridans streptococci. Four patients developed enterococcal endocarditis, 3 following urinary catheterization and one following hysterectomy.

\section{Clinical and laboratory findings}

These are summarized in Tables I and II. The infecting organism was identified in 75 patients $(95 \%)$ (Table I). Viridans streptococci accounted for 42 cases of which $6(14 \%)$ died. Mortality rose to $50 \%$ for infections with $S$. faecalis and other unusual organisms. The mean duration of symptoms before admission was longest in infection with viridans streptococci (11.1 weeks) but the range was large (1.5-28 weeks). The duration of symptoms for all organisms is shown in Table 1.

Pyrexia and a cardiac murmur were found on admission in $80 \%$ of cases. Cardiac failure was present in 32 patients of whom $9(28 \%)$ died. Seventeen patients presented with major embolic episodes and 5 $(29 \%)$ died. Mortality in patients with mitral or aortic involvement was similar: $21 \%$ and $28 \%$ respectively. Mixed aortic and mitral valve involvement did not increase the mortality ( $24 \%)$. There were 8 'late onset' cases of prosthetic valve infection (i.e. occurring more than 2 months after cardiac surgery) and $3(37 \%)$ died.

Of 65 patients in whom the ESR was measured, 14 had exhibited normal values $(<25 \mathrm{~mm} / \mathrm{h})$ and only 2 of these died. In contrast $9(53 \%)$ of 17 patients in whom the ESR was greater than $75 \mathrm{~mm} / \mathrm{h}$ died. The difference was significant $(P<0.05$, Fisher's exact test). Microscopic haematuria was found in 47 of the 72 specimens tested.

\section{Treatment}

Fifteen patients were treated with benzylpenicillin and 48 with a combination of penicillin and aminoglycoside. After 1977 streptomycin was replaced by gentamicin as the aminoglycoside of choice. Cloxacillin in combination with an aminoglycoside was used in 12 patients. Two patients with penicillin allergy $\frac{\bar{c}}{\mathrm{~s}}$ were treated with cephalosporins and one patient with $\widetilde{\nabla}$ Coxiella burnetii infection received tetracycline alone. One patient with Candida albicans infection was ${ }^{\text {s }}$ referred for emergency surgery before antimicrobial $\vec{O}$ treatment. Most surviving patients received a min- $\vec{\overrightarrow{ }}$ imum of 2 weeks intravenous therapy and the total $\stackrel{\rho}{\omega}$ treatment period was usually 6 weeks or more.

Serum trough and peak bactericidal titres were 3 measured during intravenous therapy in 32 survivors and in 7 patients who died (Figure 1) but did not $\omega$ appear to influence outcome. Among the survivors the $\omega$ serum at trough was bactericidal at a mean dilution of $\dot{\omega}$ 1 in 158 (range 2-2048) and at peak at 1 in 820 (range of $8-2048$ ). In the patients who died the serum at trough 응 was bactericidal at a mean dilution of 1 in 464 (range 16-1024) and at peak at 1 in 1074 (range 32-2048).

Eight patients had emergency valve replacement 2 and 3 of these died postoperatively.

\section{Missed diagnosis}

Among patients in whom the diagnosis was missed ifn life, there was a female preponderance of 9:4. Six patients $(46 \%)$ presented with a major arterial embolus, of whom 5 had hemiplegia. Mitral incom- $\varrho$ petence was detected on admission in 6 patients and $\overrightarrow{\bar{O}}$ considered to be insignificant. Heart failure was present in only one patient. Six had unexplained pyrexia and 3 had anaemia.

Table I Relationship of the duration of illness and outcome to the infecting organism

\begin{tabular}{|c|c|c|c|c|c|c|}
\hline \multirow[b]{2}{*}{ Organism } & \multirow{2}{*}{$\begin{array}{l}\text { No. of } \\
\text { cases }\end{array}$} & \multirow[b]{2}{*}{$(\%)$} & \multirow{2}{*}{$\begin{array}{l}\text { Percent } \\
\text { mortality }\end{array}$} & \multirow{2}{*}{$\begin{array}{c}\text { Mean age } \\
\text { years }\end{array}$} & \multicolumn{2}{|c|}{$\begin{array}{c}\text { Duration of } \\
\text { symptoms (weeks) }\end{array}$} \\
\hline & & & & & Mean & (Range) \\
\hline 'Viridans' streptococci* & 42 & $(56)$ & 14 & 52 & 11.1 & $(1.5-28)$ \\
\hline Group G streptococci & 3 & (4) & 33 & 73 & 0.33 & $(0-1)$ \\
\hline Streptococcus faecalis & 6 & (8) & 50 & 68 & 3.4 & $(0.5-12)$ \\
\hline Staphylococcus aureus & 11 & (15) & 27 & 52 & 2.8 & $(0.5-8)$ \\
\hline Staphylococcus epidermidis & 3 & (4) & 33 & 48 & 8.3 & $(1-12)$ \\
\hline Others $\dagger$ & 10 & (13) & 50 & 49 & 8 & $(1-24)$ \\
\hline
\end{tabular}

* Streptococcus bovis biotype I (9); Str. mitior (8): Str. sanguis (7); Str. mutans (3); Str. milleri (1) - identified by the Streptococcal Reference Laboratory of the Central Public Health Laboratory, Colindale; not speciated (24) †Others: Erysipelothrix rhusiopathiae, coryneform bacterium, Rothia dentocariosa, Str. pneumoniae, Haemophilus aphrophilus, Cardiobacterium hominis, Neisseria gonorrhoeae, Escherichia coli Candida albicans, Coxiella burnetii-one of each. 
Table II Presenting features and laboratory investigations in 92 cases of infective endocarditis

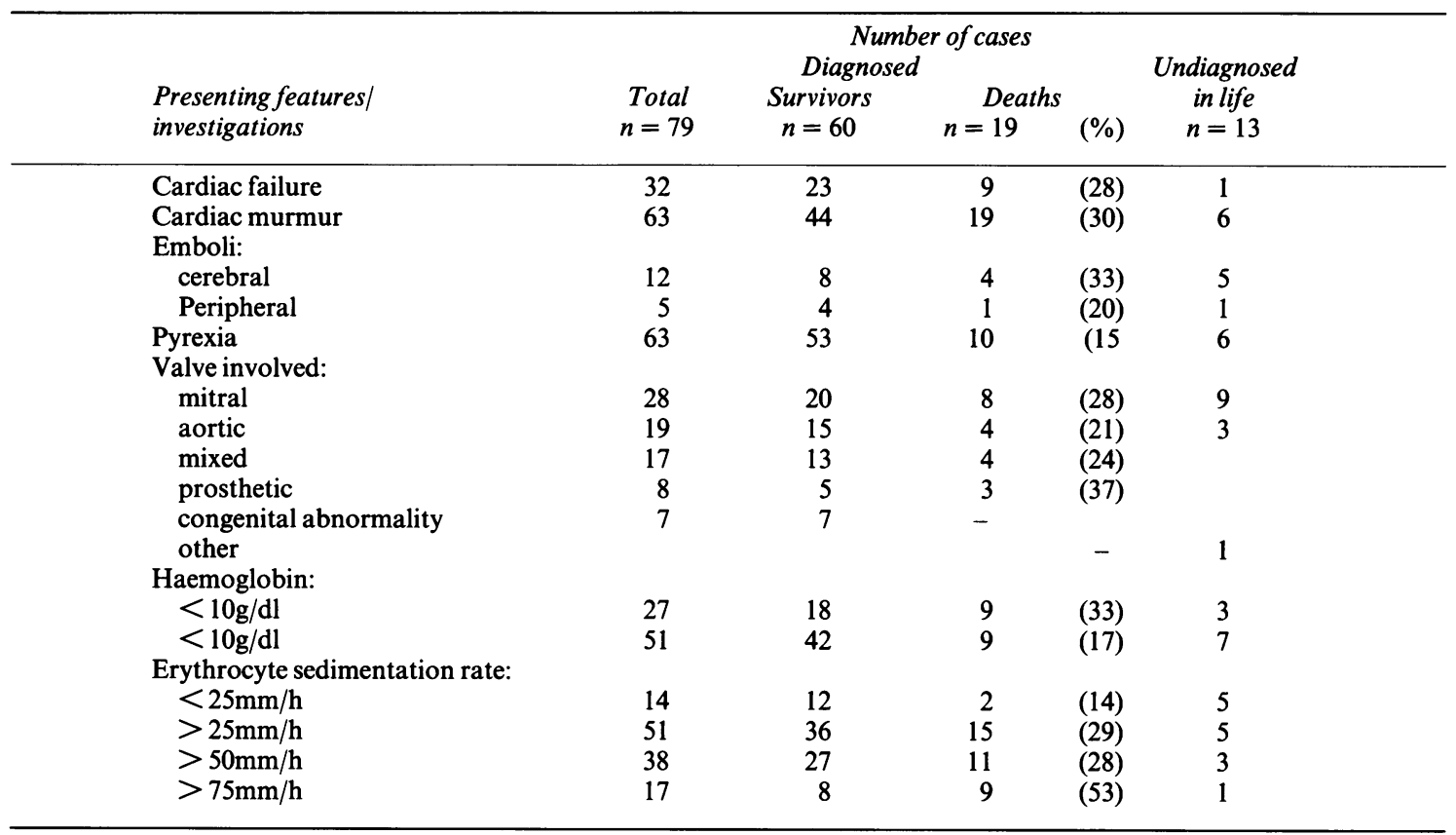

*Figures in brackets represents percentage of patients in each category who died.

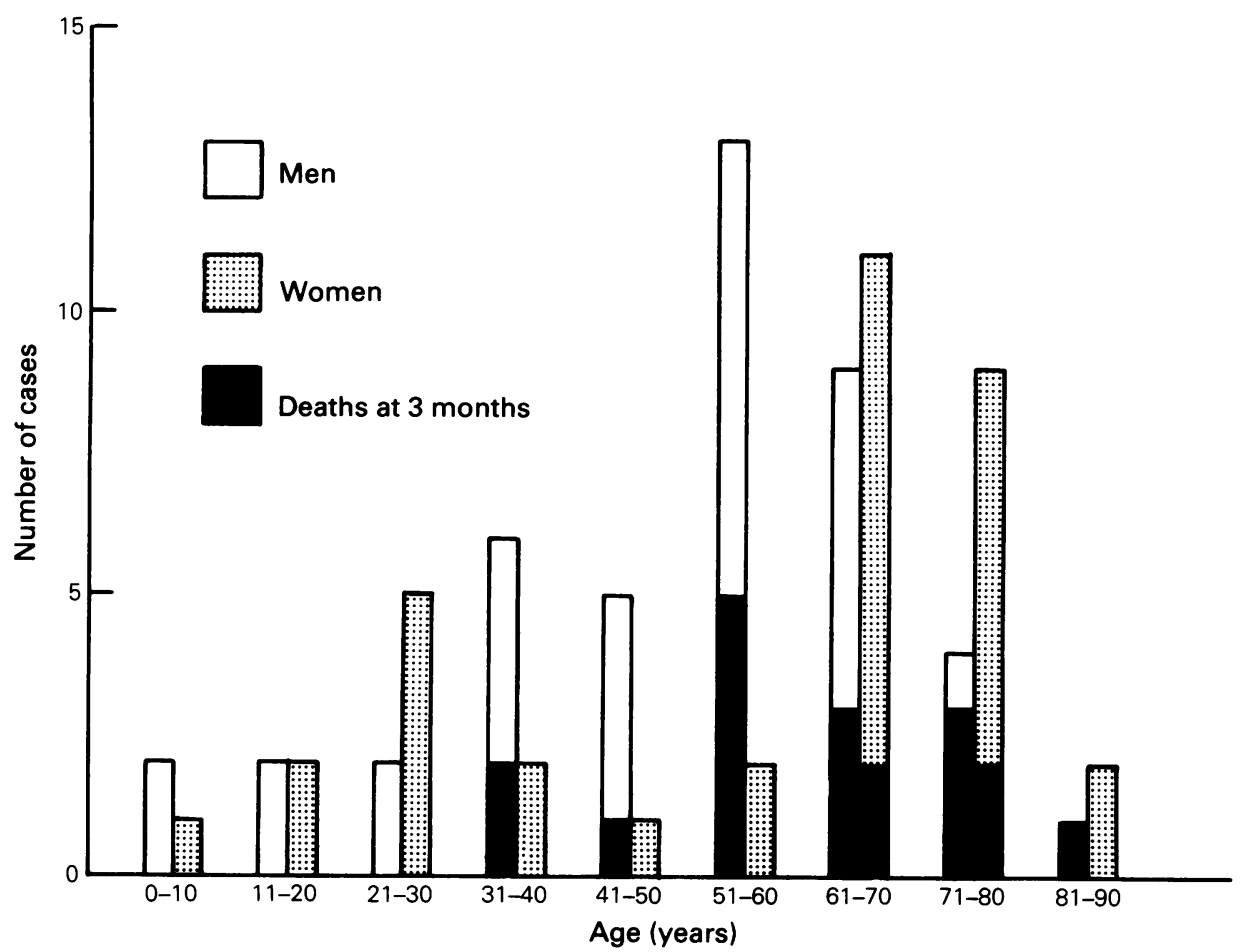

Figure 1 Relationship of age and sex to mortality in 79 cases treated for infective endocarditis. 


\section{Discussion}

Despite advances in the medical and surgical treatment of infective endocarditis mortality remains unacceptably high. ${ }^{1-3}$ Most published series have reported experience from regional secondary referral centres and a recent review from the UK presented multicentre data collected by means of a questionnaire. ${ }^{3}$ In contrast, this study has reviewed cases of endocarditis in two district general hospitals serving a well defined population. The estimated incidence of endocarditis in the locality was 16 per million per year.

The age distribution, the dominance of male cases and the higher mortality among the elderly agree with observations made by others. ${ }^{1,3,4}$ Although more men died during treatment, more of the patients who died undiagnosed were female. We obtained a bacteriological diagnosis in all but 4 of the 79 patients who were treated. A portal of entry was identified in only 8 patients $(10 \%), 4$ of whom had had recent dental surgery. This contrasts with the findings of a multicentre survey where a probable portal of entry was ascertained in $40 \%$ of cases. ${ }^{3}$ Four of our 6 cases of $S$. faecalis infection developed endocarditis in hospital following genito-urinary procedures. These should have been prevented by appropriate chemoprophylaxis. Staphylococcal infection was less common than in the other series. ${ }^{5,6}$ This may have been due to the absence of a cardiac surgical unit in our hospitals. As in other series, ${ }^{7}$ cases of viridans streptococcal endocarditis often had a protracted course of illness before admission, although there was a marked variation among patients. In contrast, infection with Group G streptococci, S. faecalis and Staph. aureus was associated with a shorter antecedent illness and tended to have a more dramatic presentation. ${ }^{8,9}$

The association between anaemia, high ESR and mortality has not been reported in other series and may simply reflect other factors such as age and chronic disease. No other investigations were helpful in predicting outcome. The proporton of patients who had microscopic haematuria $(65 \%)$ was lower than the incidence of $93 \%$ reported by Shinebourne who considered the diagnosis unlikely in its absence. ${ }^{10}$ In contrast, Lerner \& Shnurr found the incidence of haematuria to be $26 \%$ and $27 \%$ respectively. ${ }^{7,11}$

How can diagnosis be improved? Clearly the classical signs of endocarditis are not always present. In half the patients in whom the diagnosis was missed, no heart murmur was heard on admision to hospital. In the remainder mitral incompetence was detected, but considered haemodynamically insignificant. We suspect that aortic incompetence is likely to alert the clinician to the possibility of endocarditis whereas mitral incompetence, particularly in the elderly patient, may often fail to do so. Cardiac failure occurred in only one undiagnosed patient but 5 presented with cerebral embolus. A safe rule is to consider infective endocarditis in any sick patient with $\frac{3}{\mathbb{0}}$ signs of valvular incompetence, particularly those presenting with stroke.

Echocardiography is now regarded as a valuable aid to diagnosis, allowing characterization of the valve lesion and visualization of vegetations and absces-듬 ses, ${ }^{12,13}$ although a normal echocardiogram does not $\frac{\bar{m}}{7}$ exclude the diagnosis. In our series, echocardiograms $\mathbb{\Phi}$ were performed infrequently during the early years, but were used increasingly in the later years. Further- ${ }^{\infty}$ more, one hospital performed only $\mathbf{M}$ mode studies. instead of the now preferred two-dimensional echocardiograms. For these reasons it was not possible to assess the value of echocardiography in this series.

Why do patients still die of endocarditis? Uncontrolled sepsis is now uncommon and in this series there were no cases of relapsing infection. Although antibiotic therapy should be monitored by titration of $\omega$ the patient's serum, ${ }^{14}$ high bactericidal levels clearly doct not guarantee therapeutic success. Most deaths in this응 and in other series ${ }^{11,14}$ were attributable to haemodyn- amic complications arising from the valve lesion, and 3 not surprisingly, older patients are at particular risk Acute aortic incompetence is said to be the main cause $\vec{\bullet}$ of intractable cardiac failure, but in the present stude mitral valve involvement appeared equally important However, it is important to note that acute aor incompetence may not be recognized since the wêll known signs associated with chronic compensated aortic incompetence are often absent. ${ }^{15}$ Cardiac failure $\frac{}{D}$ on admission to hospital was a poor predictor of $\mathcal{Q}$ mortality, although it was the main cause of death. $\overrightarrow{\vec{B}}$ Although it may be possible to treat mild heart failure 3 by medical means most patients with this complication are at considerable risk, and certainly severe heart failure at presentation is an indication for urgent 0 surgical referral. ${ }^{16}$ Reluctance to refer such patientsbecause antimicrobial therapy has not been completed may have disastrous consequences.

Future advances in the treatment of endocarditis will require more careful liaison between microbiologist, physician and surgeon. When surgical facilities are not close at hand the physician must refer patients with $\frac{D}{O}$ cardiac failure and major arterial emboli since emergency valve replacement may offer the only hope of $\mathrm{N}$ survival.

\section{Acknowledgement}

Sincere thanks are due to our medical and surgical colleagues $\stackrel{\oplus}{\mathscr{S}}$ for permission to study patients under their care; to Nottingham P.H.L.S. laboratory for technical assistance; to $\mathrm{Dr}$ David Greenwood for advice; and to Mrs Susan Brailsford for typing the manuscript. 


\section{References}

1. Lowes, J.A., Hamer, J., Williams, G. et al. Ten years of infective endocarditis at St. Bartholomew's Hospital: analysis of clinical features and treatment in relation to prognosis and mortality. Lancet 1980, i: 133-136.

2. Smith, R.H., Radford, D.J., Clark, R.A. \& Julian, D.G. Infective endocarditis: a survey of cases in the South-east Region of Scotland, 1969-72. Thorax 1976, 31: 373379.

3. Bayliss, R., Clarke, C., Oakley, C.K., Somerville, W., Whitfield, A.G.W. \& Young, S.E.J. The microbiology and pathogenesis of infective endocarditis. Br Heart $J$ 1983, 50: 513-519.

4. Von Reyn, C.F., Levy, B.S., Arbeit, R.D., Friedland, M.D. \& Crumpacker, C.S. Infective endocarditis: an analysis based on strict case definitions. Ann Intern Med 1981, 94: 505-518.

5. Kaye, D. Changes in the spectrum, diagnosis and management of bacterial and fungal endocarditis. Med Clin North Am 1973, 57: 941-957.

6. Moulsdale, M.T., Ekyn, S.J. \& Phillips, I. Infective endocarditis. 1970-79. A study of culture positive cases in St Thomas' Hospital. $Q J$ Med 1980, 49: 315.

7. Lerner, P.I. \& Weinstein, L. Infective endocarditis in the antibiotic era. $N$ Engl J Med 1966, 274: 199-206.

8. Thompson, R.L. Staphylococcal infective endocarditis. Mayo Clin Proc 1982, 57: 106-114.
9. Wilkowske, C.J. Enterococcal endocarditis. Mayo Clin Proc 1982, 57: 101-105.

10. Shinebourne, E.A., Cripps, C.M., Hayward, G.N. \& Shooter, R.A. Bacterial endocarditis 1956-1965. Analysis of clinical features and treatment in relation to prognosis and mortality. Br Heart $J$ 1969, 31: 536-542.

11. Shnurr, L.P., Ball, A.P., Geddes, A.P., Gray, J. \& McGhie, D. Bacterial endocarditis in England in the 1970 's. A review of 70 patients. $Q J \mathrm{Med} 1977,184: 499-$ 512.

12. Roy, P., Tajik, A.J., Giulani, E.R., Schattenburg, T., Gau, G. \& Frye, R. Spectrum of echocardiographic findings in bacterial endocarditis. Circulation 1976, 53: 474-482.

13. Gilbert, B.W., Haney, R.S., Crawford, F. et al. Two dimensional echocardiographic assessment of vegetative endocarditis. Circulation 1977, 53: 346-353.

14. Gray, I.R. The choice of antibiotics for treating infective endocarditis. $Q J \mathrm{Med}$ 1975, 175: 449-458.

15. Wise, J.R., Clelland, W.P., Hallidie Smith, K.A., Bentall, H.H., Godwin, J.F. \& Oakley, C.M. Urgent aortic valve replacement for acute aortic regurgitation due to infective endocarditis. Lancet 1971, ii: 115-121.

16. Wilson, W.R., Giulani, E.R., Danielson, G.K. \& Geraci, J.E. Management of complications of infective endocarditis. Mayo Clin Proc 1982, 57: 162-170. 